\title{
Novel Assessment Method of the Critical \\ Parameters for Brewing Yeast Formulation as a Nutraceutical in Animal Diets
}

\author{
MIHAELA BEGEA ${ }^{1}$, IULIANA DIANA BARBULESCU ${ }^{2}$, LACRAMIOARA POPA ${ }^{3 *}$, \\ CARMEN OTILIA RUSANESCU ${ }^{1}$, MADALINA GEORGIANA ALBU KAYA ${ }^{4}$, \\ RAZVAN IONUT TEODORESCU ${ }^{5}$, SIMONA-IOANA MARINESCU ${ }^{2}$, MIHAI FRINCU ${ }^{2}$, \\ CONSTANTA MIHAI ${ }^{5}$, ALEXANDRU IONUT CIRIC ${ }^{1}$, ROXANA ELENA AVRAMESCU ${ }^{3}$, \\ MIHAELA VIOLETA GHICA ${ }^{3}$ \\ ${ }^{1}$ University Politehnica of Bucharest, Faculty of Biotechnical Systems Engineering, Department of Biotechnical \\ Systems, 313 Splaiul Independenței, 060042, Bucharest, Romania \\ ${ }^{2}$ Pharmacorp Innovation SRL, 313 Splaiul Unirii, 030138, Bucharest, Romania \\ ${ }^{3}$ University of Medicine and Pharmacy Carol Davila, Faculty of Pharmacy, Department of Physical and Colloidal \\ Chemistry, 2 Traian Vuia Str., 020956, Bucharest, Romania \\ ${ }^{4}$ INCDTP - Division Leather and Footwear Research Institute, Collagen Department, 93 Ion Minulescu Str., 031215, \\ Bucharest, Romania \\ ${ }^{5}$ University of Agronomic Sciences and Veterinary Medicine of Bucharest, Faculty of Land Reclamation and \\ Environmental Engineering, 59 Marasti Av., 010464, Bucharest, Romania
}

\begin{abstract}
Brewing yeast biomasses may be converted into valuable products, including supplements for ruminant diets. This paper presents experimental data on a nutraceutical suspension formulation containing postfermentation brewing yeasts and the brewing yeast strain, Saccharomyces pastorianus ssp. carlsbergensis W34/70, which was intended to be administered to ruminants. The brewing yeast biomass is a component of oral suspensions designed as dietary supplements that prevent digestive acidosis in ruminants. The brewing yeast strain W34/70 was cultivated using molasses $(M)$ and glucose $(G)$ as carbon sources and was lyophilized at different freezing temperatures $\left(0^{\circ} \mathrm{C},-10^{\circ} \mathrm{C},-20^{\circ} \mathrm{C},-30^{\circ} \mathrm{C}\right.$, and $\left.-40^{\circ} \mathrm{C}\right)$. The postfermentation brewing yeast biomass was spray dried (AAY) and lyophilized (ALY). Both dried yeast biomasses were analyzed in terms of wettability using a contact angle $\left(C A^{\circ}\right)$ evaluation at the solid/liquid interface. Suspensions were subsequently formulated and tested. Their physical and aggregative stability was established in connection with controlled sedimentation and flocculation. The assays were performed following quality by design ( $Q b D)$ principles. The critical process parameters $(C P P s)$ corresponding to the technological process of yeast production, as well as the critical quality attributes (CQAs) for suspension formulations, were pointed out as preamble determinants when designing oral nutraceuticals destined to be included in ruminant diets.
\end{abstract}

Keywords: brewing yeast biomass; contact angle; nutraceuticals; powder wettability; suspension formulation

Yeasts have been widely used for the production of various products, such as beer, wine, bread, biofuels, and biopharmaceuticals, due to their diverse and dynamic properties. The use of $S$. cerevisiae in controlled fermentations is based on its characteristics: the efficient production of high ethanol amounts, fermentation as a preferential metabolic pathway, its higher ethanol tolerance, and the presence of other environmental stresses [2]. On an industrial scale, brewing yeast is a raw material used to obtain proteins, amino acids, and vitamins, and is nowadays introduced in animal feed $[11,24]$. With respect to the yeast cell, the most important components are found in its wall, which contains glucan, mannan, and a protein fraction. Their separation is simple and inexpensive, but since the yield of its pure fraction is only $65 \%$, these compounds are produced at low levels of purity and are marketed as animal feed nutritional supplements [13]. Following this, residual brewing yeast, which is rich in content in organic matter including high total nitrogen levels and a protein content by almost $50 \%$ dry mass - demonstrates potential use in industrial bioprocesses [3, 15]

Yeasts and fungal probiotics such as Saccharomyces and Aspergillus have generated good results in adult ruminants by preventing lactate accumulation in the rumen and providing growth factors (organic acids and vitamins) [11]. Many studies on the inclusion of active yeast in animal nutrition were carried out $[9,17,14,20,22,30]$, revealing that the effect of yeast biomass ingestion differs from one species to another. In the case of cows and other ruminants, introducing active yeast to their diets helps prevent the post-feeding $p \mathrm{H}$ drop; thus, one of the best developed marketing fields to use yeasts as part of a supplementary diet is the food manufacturing industry for ruminants, since ruminants ingest a large amount of rapidly fermented carbohydrates. Only some strains are capable of preventing $\mathrm{pH}$ level decreases (acidosis). Therefore, available products vary widely in terms of their formulation, mainly by the $S$. cerevisiae strain, and also by the number and viability of yeast cells $[18,30]$.

*email: lacramioara.popa@umfcd.ro 
Problems concerning the marketing of yeast biomasses occur because these products have a short preservation time, high contamination risks, and large shipping and storage costs. Lyophilization and atomization are considered suitable methods for yeast drying $[4,19]$.

The characteristics of these suspensions, including heterogenous deflocculated/flocculated disperse systems, are widely known, as are their undesired instability (sedimentation or "caking") that result from particle interactions, which prevent easy redispersion. For a suspension to be accepted, it should display partial flocculation/controlled flocculation [10, 25, 28]. Since these suspensions are considered to be thermodynamically unstable, their stability assessments revolve around controlled sedimentation and flocculation [5, 12].

When exploring yeast suspensions and their possible instability, it is important to note that yeast flocculation is a cellular aggregation process, in which cells adhere reversibly to one another, forming macroscopic flocs. This process causes the yeast to sediment/cream at the end of the fermentation process. The mechanisms involved in colloidal dispersion sedimentation and creaming are different. Yeast flocculation is a biological, chemical, and physical process, depending on the expression of specific flocculation genes. Turbidimetric tests suggest that flocculation in bottom-fermenting yeasts (not in top-fermenting yeasts) is a lectin-aggregating mechanism [7]. The initial definition of yeast flocculation is "the phenomenon wherein yeast cells adhere in clumps and either sediment from the medium in which they are suspended or rise to the mediums surface" $[8,27]$. Also, chain formation is known to occur in yeast suspensions [26]. Flocculation occurs in the absence of cell division and only a tiny amount of calcium ions is necessary for it to occur.

The following study explored the use of yeast suspensions as nutraceuticals in ruminant diets while considering Quality by Design (QbD) evaluation tools, which help to assess certain problems that may occur during the product's development. QbD is an essential tool that enables one to develop an understanding of the process as a constitutive part of product quality and performance. It reunites numerous factors that need constant verification and improvement along a product's development stages. Furthermore, quality should be imbedded in the fabrication process and in the final product. This statement fosters the idea that critical process parameters (CPPs) in correspondence with critical quality attributes (CQAs) need to be incorporated as integrated parts of the formulation, drug design, and development processes $[1,16,23,29]$.

\section{Materials and methods}

The $S$. pastorianus ssp. carlsbergensis W34/70 yeast strain was purchased from Hefebank Weihenstephan (Au in der Hallertau, Germany). The post-fermentation brewing yeast biomass was collected from the Bergenbier S.A. brewery (Ploiești, Romania) and was provided by Agsira S.R.L. The molasses was obtained from the sugar factory LEMARCO CRISTAL S.R.L. (Urziceni, Romania). Agar-agar, Tween 20, glucose, yeast extract, malt extract, Peptone $\mathrm{Hy}-\mathrm{Soy}, \mathrm{KCl}, \mathrm{MgCl}_{2}$, and $\mathrm{NH}_{4} \mathrm{OH}$ were obtained from Sigma-Aldrich Co. (St. Louis, MO, USA).

The culture media used during the experiments were as follows: culture medium YMSP based on yeast extractmalt extract-sucrose-Peptone Hy-Soy-agar for strain conservation; culture medium YPG based on yeast extractglucose-Peptone Hy-Soy-agar for pre-inoculum and inoculum (submerged culture) prepared in cases where experiments used glucose as a carbon source; and culture medium YMP based on yeast extract-malt extract-Peptone Hy-Soy for the inoculum (submerged culture) prepared in cases where experiments used molasses as a carbon source.

The pre-inoculum culture was obtained from the stock culture in a MEMERT incubation chamber. The inoculum was obtained using a Unimax 1010 orbital shaker-incubator 1000 (Heidolph, Schwabach, Germany).

The fermentation process was performed in a batch culture system, using two pilot fermenters, namely a $4 \mathrm{~L}$ operational capacity Biostat B fermenter from Sartorius (Germany) and a 4 L operational capacity fermenter from Applikon Biotechnology (Delft, the Netherlands). The steps and cultivation parameters were as follows: the stock culture and the pre-inoculum were obtained in tubes containing $10 \mathrm{~mL}$ of sloped solid culture medium following $30^{\circ} \mathrm{C}$ incubation for $48 \mathrm{~h}$. The liquid inoculum was obtained in $500 \mathrm{~mL}$ Erlenmeyer bottles containing $150 \mathrm{~mL}$ of culture medium after $18-20 \mathrm{~h}$ of incubation at $28^{\circ} \mathrm{C}-30^{\circ} \mathrm{C}$ in a submerged system $(140 \mathrm{rpm})$. The inoculation rate for the inoculum was 1-2 tubes/Erlenmeyer flasks; and fermentation was conducted in compliance with the following parameters: cultivation time, $18-23 \mathrm{~h}$; temperature, $28^{\circ} \mathrm{C}-30^{\circ} \mathrm{C} ; p \mathrm{H}, 4-5 ; 300 \mathrm{rpm}$. The post-fermentation process involved biomass separation by centrifugation, using a Thermo Scientific Sorvall ST $16230 \mathrm{~V}(4 \times 400 \mathrm{~mL})$ centrifuge at 3,500-4,000 rpm for 5-10 mins. Repeated washing of the biomass with distilled water was performed. The resulted purified biomass was dried through lyophilization or spray dying.

The monitored biotechnological parameters were as follows: temperature, stirring speed, pH levels, and broth dry matter during fermentation. The $p \mathrm{H}$ level was corrected with $\mathrm{NH}_{4} \mathrm{OH} 5 \%$ solutions, which were filtered through preweighed $13 \mathrm{~mm}$ membrane filters $(0.45 \mu \mathrm{m}$ pore size; Nalgene, Thermo Fisher Scientific, Waltham, MA, USA). The dried samples were coded according to the used carbon source and freezing temperature during lyophilization. The biomass containing the yeast $S$. pastorianus ssp. carlsbergensis W34/70 with molasses as a carbon source was coded as M-0, M-10, M-20, M-30, or M-40; the biomass containing the yeast S. pastorianus ssp. carlsbergensis W34/70 with glucose as a carbon source was coded as G-0, G-10, G-20, G-30, or G-40; and spray-dried and lyophilized postfermentation brewing yeasts were abbreviated AAY and ALY, respectively. The yeast biomass samples were dried 
through lyophilization and spray drying. The post-fermentation brewing yeast was dried through spray drying and lyophilization, and the yeast biomass containing S. pastorianus ssp. carlsbergensis W34/70 was dried through lyophilization using varying freezing temperatures. Lyophilization was carried out using a Martin Christ, DELTA 224 LSC (Germany) lyophilizer and spray drying was achieved using an A/S Niro Anhidro spray dryer (Denmark).

\section{Experimental results}

Yeast biomass lyophilization and spray drying

The S. pastorianus ssp. carlsbergensis W34/70 yeast biomass obtained with glucose and molasses as carbon sources was lyophilized at various freezing temperatures: $0^{\circ} \mathrm{C},-10^{\circ} \mathrm{C},-20^{\circ} \mathrm{C},-30^{\circ} \mathrm{C}$, and $-40^{\circ} \mathrm{C}$. Figure 1 illustrates the lyophilization protocol and the conditions under which the samples of brewing yeast biomass were developed. The post-fermentation brewing yeasts were dried as follows: ALY was molded into $200 \mathrm{~mL}$ glass Petri dishes and dried through lyophilization following the protocol presented in Figure 1. AAY was spray-dried at 2 bar pressure, $210^{\circ} \mathrm{C}$ entrance temperature, and $230^{\circ} \mathrm{C}$ exit temperature.

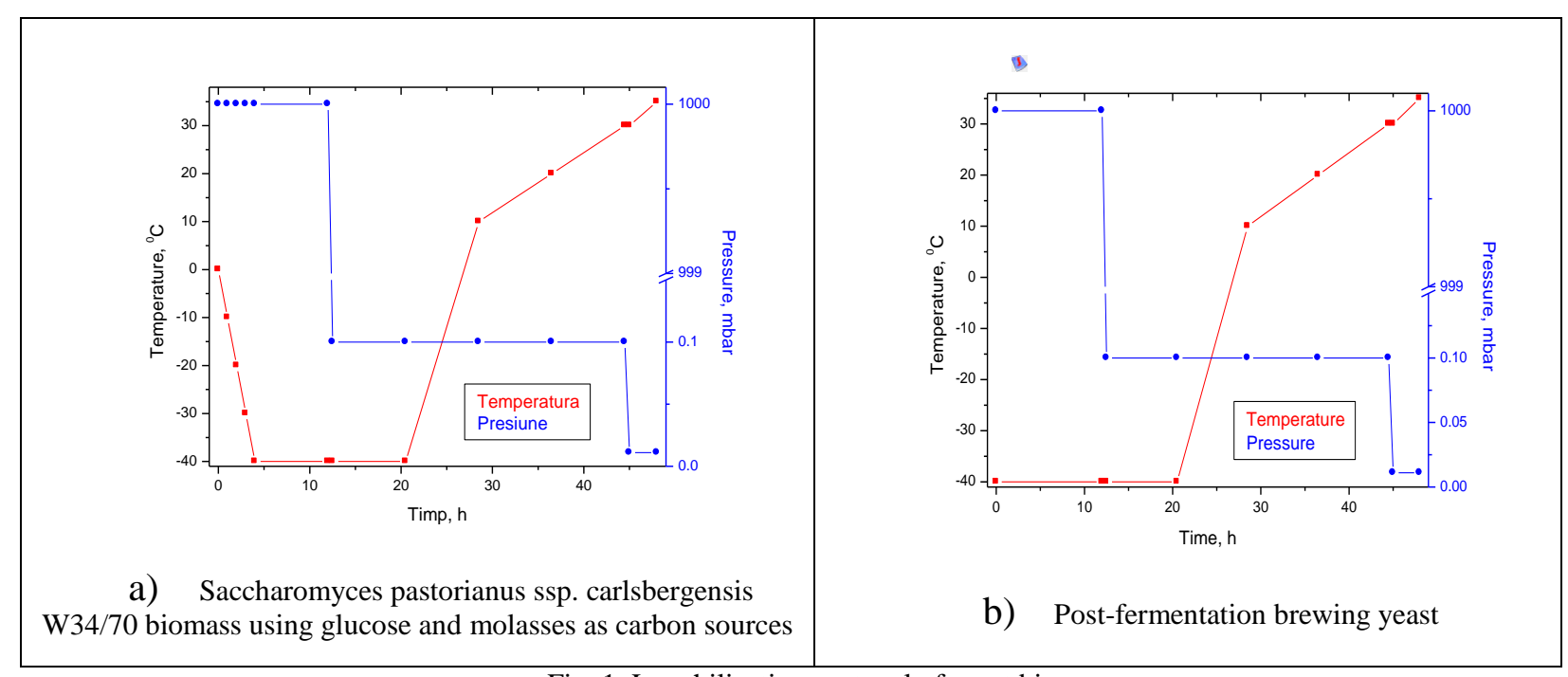

Fig. 1. Lyophilization protocol of yeast biomass

\section{Contact angle evaluation}

Dried $S$. pastorianus ssp. carlsbergensis W34/70 yeast biomass samples were evaluated from a wettability point of view (contact angle). The evaluation was based on the KSV CAM 101 Scientific goniometer routine. Measurements were carried out at room temperature. Determination of the contact angle was carried out using a previously described protocol (Violeta Ghica et al. 2016): (i) dried samples were grounded into a powder; (ii) they were uniformly distributed in a thin layer on a glass microscope blade, previously covered with double adhesive tape; (iii) the distilled water droplet was dispersed on the powder's surface through a 1,000 $\mu \mathrm{L}$ Hamilton syringe (using a C209-22 needle; Biolin Scientific, Gothenburg, Sweden); and (iv) the droplet's evolution in time is evaluated through images captured by a camera (contour area visualization) [21]. Analysis of the phenomena occurring at the droplet-powder bed interface highlights droplet shape changes, as illustrated through contact angle variations (hysteresis). The actual calculation is based on recorded frames at a certain speed (16 ms interval). Five, 20, or 40 frames (images) were captured, depending on the droplet's behavior.

Each contact angle measurement accounted for the droplet's volume and was performed at baseline (considered to be the solid-liquid interface). The droplet's shape was monitored using a digital camera connected to the CAM 101 goniometer, which allowed for a fitting curve of the actual drop shape. Further characterization was performed using the contact angle value $\left(\theta_{\mathrm{e}}\right)$, calculated with the help of Young's equation (1.1):

$$
\cos \theta_{\mathrm{e}}=\frac{\gamma_{\mathrm{SA}}-\gamma_{\mathrm{SL}}}{\gamma_{\mathrm{LA}}}
$$

where $\gamma_{\mathrm{SA}}, \gamma_{\mathrm{SL}}$, and $\gamma_{\mathrm{LA}}$ stand for the interfacial tensions, at equilibrium, characterizing a liquid droplet deposited on a solid surface.

In the case of powder beds - which are imperfect, non-homogenous surfaces - a more accurate approach is represented by an apparent contact angle $\left(\theta_{\mathrm{a}}\right)$, calculated as an average value of the equilibrium contact angles $\left(\theta_{\mathrm{e}}\right)$ [1] .

\section{Yeast biomass suspension preparation}

The dried S. pastorianus ssp. carlsbergensis W34/70 yeast samples were directly incorporated, as a solid phase, in distilled water and mixed together. As previously noted, dried samples of yeast biomass were grounded, with the aim of obtaining a homogenous powder. Afterwards, the samples were immediately weighed to assess the yield. The 
suspension formulations were designed according to the literature data to achieve a simple composition to detect the factors influencing the formulation.

The design composition proposed for the suspensions includes the following: freeze-dried yeast powder $4 \%(\mathrm{w} / \mathrm{w})$ - molasses carbon source M0, M-10, M-20, M-30, and M-40; glucose carbon source - G0, G-10, G-20, G-30, and G40; post-fermentation brewing - AAY and ALY yeast biomass; Tween $20(0.4 \% \mathrm{w} / \mathrm{w})$ as a wetting agent, and a nontoxic and non-irritant surfactant; and Agar-agar (2\% w/w) as a viscosity-increasing agent. All suspensions were prepared using distilled water as a liquid medium to a volume of $25 \mathrm{~mL}$ at $25^{\circ} \mathrm{C}$.

\section{Sedimentation, flocculation degree, and redispersibility analysis}

Suspensions were kept at rest for $24 \mathrm{~h}, 48 \mathrm{~h}$, and $5 \mathrm{~d}$, respectively, at room temperature. Afterwards, their kinetic (sedimentation analysis) and aggregative stabilities (redispersibility degree and flocculation degree) were assayed. Sediment volumes $\left(\mathrm{V}_{\mathrm{n}}\right)$ were measured and rated to the total suspension volume $\left(\mathrm{V}_{0}\right)$ to calculate the sedimentation degree $\left(F_{n}\right)(1.2)$.

$$
\mathrm{F}_{\mathrm{n}}=\frac{\mathrm{V}_{\mathrm{n}}}{\mathrm{V}_{0}}
$$

The flocculation degree $(\beta)$ was evaluated using the following equation (1.3):

$$
\beta=\frac{F_{n}}{F_{\infty}},
$$

where $\mathrm{F}_{\infty}$ is the sedimentation volume after $5 \mathrm{~d}$.

Redispersibility (r) was indicated by $180^{\circ}$ rotations of the suspension bottles. Each suspension was maintained upside down for about $2 \mathrm{~s}$, followed by a return to the initial position (full cycle). These turns and returns were repeated until a complete redispersion of the suspension was observed. It is preferable that the suspensions are homogeneous, as they were at the initial preparation time. One cycle corresponds to a $100 \%$ redispersibility degree. With each cycle of return, the redispersibility level drops with 5\% (for instance, two cycles correspond to 95\% redispersibility, and so on). These measurements were repeated after $48 \mathrm{~h}$ and $5 \mathrm{~d}$ after preparation.

\section{pH measurements}

The $\mathrm{pH}$ values of the yeast suspensions were determined immediately following preparation, as well as after $24 \mathrm{~h}$, $48 \mathrm{~h}$, and $5 \mathrm{~d}$ from the time the suspensions were prepared, using the Oakton digital $\mathrm{pH}$ meter. Values were measured at $25^{\circ} \mathrm{C}$ (room temperature).

\section{Yeast biomass lyophilization and spray-drying assessment}

W34/70 yeast samples were dried through lyophilization ( $\mathrm{M}$ and $\mathrm{G}$ series) at different temperatures $\left(0^{\circ} \mathrm{C},-10^{\circ} \mathrm{C},-\right.$ $20^{\circ} \mathrm{C},-30^{\circ} \mathrm{C}$, and $-40^{\circ} \mathrm{C}$ ). The post-fermentation yeast biomass was dried by spray drying (AAY) and thorough lyophilization (ALY), respectively. Concerning lyophilization at different freezing temperatures, a low yield (below $10 \%$ ) was obtained, compared to the spray-drying (atomization) process. In order to obtain a better drying yield, the spray-dryer nozzle must be changed or lower concentrations of yeast biomass should be used. The macroscopic analysis of the freeze-dried yeasts shows that the samples are brittle, yellowish, and have a distinct, characteristic odor.

\section{Wettability evaluation}

From a wettability point of view, a powder is best characterized by its contact angle, although there are some inconveniences associated with porosity. The contact angle $\left(\mathrm{CA}^{\circ}\right)$ is the quantitative expression of a solid's wetting degree. The "sessile drop" method was chosen for the experimental evaluation [16]. This method is simple, reproducible, and uses a small amount of powder, which is advantageous since the drying yield was $<10 \%$.

A contact angle $<90^{\circ}$ indicates that surface wetting is favored and the fluid spreads over a large area, while contact angles $>90^{\circ}$ reveal that the surface wetting is unfavorable, so the fluid minimizes its contact with the surface, forming a compact liquid droplet.

The wettability assessment results for freeze-dried yeast obtained from S. pastorianus ssp. carlsbergensis W34/70 biomass are presented in Table 1, with the average contact angle values $\left(\mathrm{CA}^{\circ}\right)$ corresponding to the $\mathrm{M}$ and $\mathrm{G}$ yeast powders series. The corresponding contact angle values for post-fermentation brewing yeast (AAY and ALY) are also included.

Table 1

AVERAGE CONTACT ANGLE $\left(\mathrm{CA}^{\circ}\right)$ VALUES

\begin{tabular}{|rrrrrrrrrrrrr|}
\hline $\begin{array}{r}\text { Yeast } \\
\text { Sample }\end{array}$ & M0 & M-10 & M-20 & M-30 & M-40 & G0 & G-10 & G-20 & G-30 & G-40 & AAY & ALY \\
\hline CA $\left(^{\circ}\right)$ & 41.13 & 49.60 & 31.33 & 28.17 & 29.03 & 36.02 & 40.85 & 33.68 & 37.60 & 42.25 & 68.13 & 26.76 \\
\hline
\end{tabular}


A selection of the corresponding images to the measured contact angles for the tested yeast samples recorded by the CAM101 goniometer, at different time intervals, are illustrated in Figures 2, along with the contact angle hysteresis. Time intervals are selected so that the contact angle variations are visible.

\section{Sedimentation, flocculation, redispersibility, and $\mathrm{pH}$ analysis}

The yeast powders were included as dispersed phases in the suspension formulations. This stage of the study represents a preliminary investigation in designing new suspension formulations. The proposed composition was simple, so as to minimize unwanted interactions.

After preparation, the macroscopic analysis of the suspensions revealed a yellowish-grey color and opacity. A distinct, characteristic odor was also noted. At room temperature, the suspensions maintained their stability up to $5 \mathrm{~d}$ without the use of any preservatives. All results regarding kinetic stability parameters are listed in Table 2.

Table 2

RESULTS SUMMARY: SEDIMENTATION (VN-SEDIMENT VOLUME), REDISPERSIBILITY $(R)$, FLOCCULATION DEGREE (B) ANALYSES, AND PH MEASUREMENTS

\begin{tabular}{|c|c|c|c|c|c|c|c|c|c|c|c|c|}
\hline \multicolumn{2}{|c|}{ Preparation } & \multicolumn{4}{|c|}{$24 \mathrm{~h}$} & \multicolumn{4}{|c|}{$48 \mathrm{~h}$} & \multicolumn{3}{|c|}{5 days } \\
\hline Yeast & $\mathrm{pH}$ & $\mathrm{V}_{\mathrm{n}}(\mathrm{mL})$ & $r(\%)$ & $\beta$ & $\mathrm{pH}$ & $\mathrm{V}_{\mathrm{n}}(\mathrm{mL})$ & $r(\%)$ & $\beta$ & $\mathrm{pH}$ & $\mathrm{V}_{\mathrm{n}}(\mathrm{mL})$ & $r(\%)$ & $\mathrm{pH}$ \\
\hline M0 & 5.11 & 10.50 & 85 & 1.05 & 4.85 & 11.00 & 90 & 1.10 & 4.88 & 10.00 & 75 & 5.39 \\
\hline M-10 & 5.06 & 10.50 & 85 & 0.93 & 4.87 & 11.50 & 85 & 1.02 & 4.92 & 11.25 & 80 & 5.10 \\
\hline M-20 & 5.07 & 11.00 & 65 & 1.00 & 4.91 & 11.50 & 65 & 1.04 & 4.95 & 11.00 & 85 & 5.14 \\
\hline M30 & 5.14 & 11.50 & 55 & 0.95 & 4.95 & 12.50 & 80 & 1.04 & 4.97 & 12.00 & 75 & 5.23 \\
\hline M-40 & 5.14 & 11.00 & 70 & 1.04 & 4.88 & 12.00 & 70 & 1.14 & 4.94 & 10.50 & 65 & 5.20 \\
\hline G0 & 5.08 & 12.00 & 100 & 1.17 & 4.71 & 10.50 & 85 & 1.02 & 4.73 & 10.25 & 75 & 5.23 \\
\hline G-10 & 5.15 & 12.00 & 95 & 1.20 & 4.72 & 11.00 & 75 & 1.10 & 4.76 & 10.00 & 60 & 5.22 \\
\hline G-20 & 5.12 & 10.75 & 75 & 1.07 & 4.79 & 11.75 & 85 & 1.17 & 4.80 & 10.00 & 80 & 5.08 \\
\hline G-30 & 5.07 & 11.25 & 95 & 1.18 & 4.65 & 10.50 & 80 & 1.10 & 4.69 & 9.50 & 90 & 5.19 \\
\hline G-40 & 5.18 & 10.50 & 75 & 1.10 & 4.70 & 11.00 & 85 & 1.15 & 4.71 & 9.50 & 90 & 5.00 \\
\hline AAY & 4.89 & 12.00 & 95 & 1.09 & 4.93 & 11.00 & 95 & 4.92 & 4.89 & 12.00 & 95 & 1.09 \\
\hline ALY & 5.09 & 10.50 & 90 & 1.00 & 5.24 & 10.50 & 90 & 5.28 & 5.09 & 10.50 & 90 & 1.00 \\
\hline
\end{tabular}

Sedimentation, flocculation degree, and redispersibility analysis for the $M$ series tested suspensions were as follows:

- After $24 \mathrm{~h}$ : A sediment was deposited at the bottom of the suspension, displaying a high flocculation degree, especially for the M-20 and M-40 samples. The supernatant liquid was cloudy. Redispersion was difficult for these two samples, but happed fast in M0 and M-10. About two-thirds of the sediment was easily dispersed, while the remaining one-third was difficult to redisperse (especially for M-30, where redispersibility [r] had the lowest value [55\%]). The "caking" (calcification) phenomenon took place in the lower part of the sediment.

- After $48 \mathrm{~h}$ : The deposited sediment was clearly delimited, especially at M-0, M-10, and M-20. The supernatant for the M-30 and M-40 suspensions was not clear. Redispersion was relatively difficult to achieve, except for M0, which was easier to redisperse than after $24 \mathrm{~h}$.

- After $5 \mathrm{~d}$ : The supernatant was clearly separated from the sediment. The supernatant was darker compared to the $\mathrm{G}$ series. Also, the smell was most pungent compared to the previous days, indicating an advanced degree of fermentation. Redispersibility is much more difficult compared to the previous analyses.

The following points detail the sedimentation, flocculation degree, and redispersibility analysis for $\mathrm{G}$ series tested suspensions:

- After $24 \mathrm{~h}$ : The opaque supernatant was not yet clearly delimited from the sediment. Redispersion happened quickly for G0, G-10, and G-30 and was difficult for G-20 and G-40.

- After $48 \mathrm{~h}$ : The sediment was well delimited and the supernatant was clear. Redispersibility was more difficult than after $24 \mathrm{~h}$.

- After $5 \mathrm{~d}$ : The sediment displayed the lowest volume. Redispersion was more difficult to achieve G0, G-10, and G-30 and was easier for G-20 and G-40. Similar to what occurred in the M series, the supernatant displayed a darker yellow color.

The following points detail the sedimentation, flocculation degree, and redispersibility analysis for the AAY and ALY yeast suspensions:

- After $24 \mathrm{~h}$ : The supernatant was clear in both the AAY and ALY suspensions. The sediments were compact, but easily redispersible. The particles forming the sediment were smaller and more uniform in size when compared to the $\mathrm{M}$ and $\mathrm{G}$ series. This was also highlighted after the wettability assessment. Redispersibility was easily achieved for both suspensions.

- After $48 \mathrm{~h}$ : The supernatant was clear, and the sediment was grey and well delimited. Redispersibility was the same as it was after $24 \mathrm{~h}$ for both samples. 
- After $5 \mathrm{~d}$ : Color intensification was noticed in the supernatant, as was found in the M and G series. Also, the ring separating the supernatant from the sediment appeared to be more compact. Redispersion was as easy as in the first assessment, demonstrating high stability for the model suspensions.

The sedimentation, flocculation, and redispersibility analysis for AAY and ALY suspensions indicated a very good redispersibility (95\% and $90 \%$, respectively) after $24 \mathrm{~h}$ from preparation.

Overall, the powders were analyzed for wettability (hydrophilicity/hydrophobicity) through a contact angle evaluation $\left(\mathrm{CA}^{\circ}\right)$. The evaluation was performed using distilled water as a liquid model, which was later used as a vehicle for the suspension's preparation. Contact angle values were $<90^{\circ}$, indicating a good wetting degree of the analyzed powders (hydrophilicity). Moreover, since the powders are easily wetted by water, which also represents the suspension vehicle, the dispersion system will be homogenous and easily redispersible. The suspensions will also display stability over time, meaning that the proposed formulation design represents a reliable model as a nutraceutical suspension. The yeast powders were incorporated as internal phases of proposed nutraceutical suspensions (4\% concentration). The other components, as well as other operational parameters, were kept constant to highlight the influence of each formulation factor.

For the yeast biomass cultivated on molasses $(\mathrm{M})$ as a carbon source, the changes observed in the wetting degree correlated with the redispersibility evolution from the moment of preparation until day 5 of the analysis, where M0 and M-10 corresponded to higher contact angles than M-20 and M-30, and they also displayed a low redispersibility degree $(r)$. M-20 and M-30 showed low contact angles and an easy redispersion (high redispersibility degree, $r$ ). M-40 presents a low $\mathrm{CA}^{\circ}$, a low $\beta$, and it did not comply with the previous pattern (i.e., a high CA corresponds to a low $\mathrm{r}$ and a low $\mathrm{CA}^{\circ}$ corresponds to a high $r$ ).

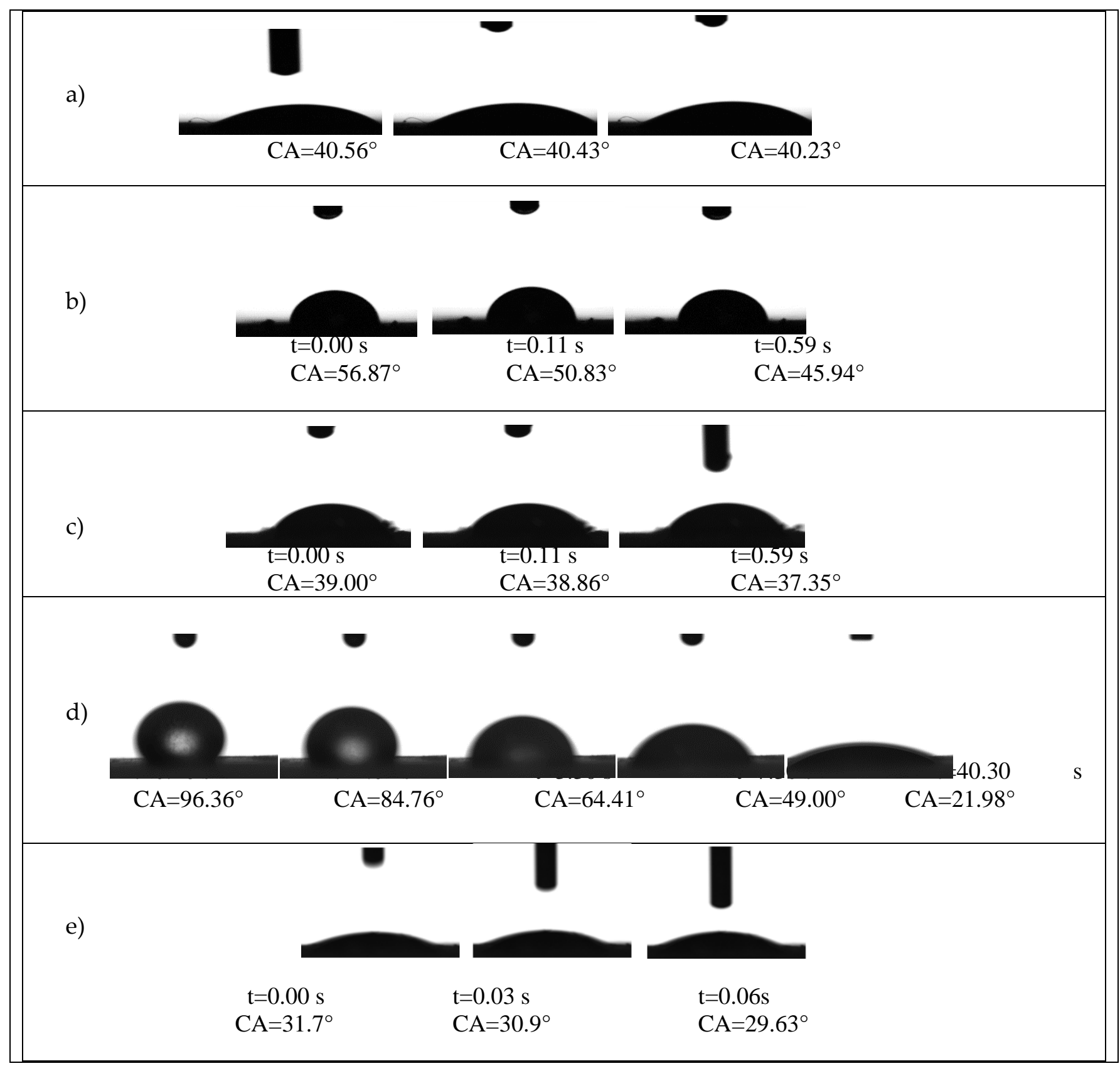

Fig. 2. a) M0 yeast sample b) M-10 yeast sample c) G-10 yeast sample d) AAY yeast sample e) ALY yeast sample 
For the yeast biomass cultivated on glucose $(\mathrm{G})$ as a carbon source, the changes observed in wetting degree, from the moment of preparation until day 5 of the analysis, were as follows: G0, G-10, and G-30 corresponded to high CA ${ }^{\circ}$ values and a low $r$; G-20 displayed a low CA value and a high $r$; and G-40 behavior was the reverse of M-40, displaying a high $\mathrm{CA}^{\circ}$ and high $r$.

These contact angle values changes indicated a marked influence of the use of a carbon source (molasses or glucose) on the hydrophilic characteristics of the yeast powder. Secondly, within each series, the influence of freezing temperature on the wetting degree was noted. A wetting degree around $\leq 30^{\circ}$ was evident in the suspensions with a high redispersibility.

Sedimentation, flocculation, and redispersibility analyses for the M and G suspension series indicated that optimal lyophilization temperatures were $-10^{\circ} \mathrm{C}$ when molasses was used as a carbon source and $-30^{\circ} \mathrm{C}$ when using glucose as a carbon source. Optimal temperatures were chosen given the high degree of redispersibility (85\% and $95 \%$, respectively), as displayed by the two suspensions after $24 \mathrm{~h}$ from the moment of reconstitution.

Optimal lyophilization parameters were selected from a redispersibility point of view, in relation to suspensions evaluated after $24 \mathrm{~h}$ from preparation. This is due to the fact that the suspension should be reconstituted immediately before administration (ex tempore).

AAY and ALY brewing yeast powders displayed hydrophilicity, which was higher in ALY $\left(\mathrm{CA}=26.76^{\circ}\right)$ than in AAY $\left(\mathrm{CA}=68.13^{\circ}\right)$. From a kinetic stability point of view, the AAY and ALY suspensions demonstrated very good redispersibility (95\% and 90\%, respectively) $24 \mathrm{~h}$ after preparation. These values were also maintained through the next assays (after $48 \mathrm{~h}$ and $5 \mathrm{~d}$ after the suspensions were reconstituted), thus displaying high stability over time.

The suspensions were also evaluated in terms of their $p H$ levels. Both molasses $(\mathrm{M})$ and glucose $(\mathrm{G})$ yeast suspensions demonstrated a relative $\mathrm{pH}$ decrease, especially in the first $24 \mathrm{~h}$. This phenomenon was justified by alcoholic fermentation and is followed by an increase in $\mathrm{pH}$ values resulting from agitation and also due to the fact that the bottles were kept closed and no aeration was possible.

\section{Conclusions}

This study provides a setting of $\mathrm{QbD}$ criteria for further application in analyzed yeast biomass suspensions indicated for dietary administration to young animals. The processing parameters that should be followed to obtain high yeast yields (CPPs) are as follows: primary nutrients, carbon source, and cultivation parameters (agitation rate, airflow, freezing temperature through drying, and $\mathrm{pH}$ ). Lyophilization/spray drying parameters are established based on the type of yeasts. In addition, the CQAs for the suspension formulations are proposed and include the following: good wettability degree of the yeast powders, expressed as a low contact angle (hydrophilic powder with CA around $\leq 30^{\circ}$ ); redispersibility between $95 \%$ and $85 \%$; as well as minimization/absence of the "caking" phenomenon, which was highlighted during the $48 \mathrm{~h}$ and $5 \mathrm{~d}$ stability assays. A correlation between wettability studies and the suspensions' kinetic behavior within $24 \mathrm{~h}$ after preparation allowed for optimal formulation design. The freezing temperature applied during the drying process was established as optimal at $-30^{\circ} \mathrm{C}$ for the $\mathrm{G}$ series and $-10^{\circ} \mathrm{C}$ for the $\mathrm{M}$ series. The chosen temperatures accounted for the fact that the suspensions are meant to be administered ex tempore. These analyses provide an initial profile of the brewing yeast biomass as a promising alternative when deriving high-yield products with optimal technological parameters and enhanced stability, allowing for their administration as nutraceuticals in ruminants. This novel method is useful to highlight the critical process parameters and critical quality attributes that are essential in the production of suspension formulations that are most suitable as oral nutraceuticals for ruminants.

Acknowledgments: This work was funded by the Romanian Executive Agency for Higher Education, Research, Development and Innovation Funding (UEFISCDI) (Bridge Grant 26BG/2016 - PN-III-P2-2.1-BG-2016-0308). We also thank the company AGSIRA SRL for providing samples of post-fermentation brewing yeast biomass. English-language editing of this manuscript was provided by Journal Prep Services.

\footnotetext{
References

1.ALGHUNAIM, A., S. KIRDPONPATTARA AND B.Z. NEWBY. Powder Technol. 287: 201-215, 2016

2.BASSO, R.F., A.R. ALCARDE AND C.B. PORTUGAL. Food. Res. Int. 86: 112-120, 2016

3.BERLOWSKA, J., M. DUDKIEWICZ-KOŁODZIEJSKA, E. PAWLIKOWSKA, K. PIELECH-PRZYBYLSKA, M. BALCEREK A. CZYSOWSKA AND D. KREGIEL. J. Inst. Brew. 123: 396-401, 2017.

4.DE A SILVA, J., M.I.S. MACIEL, N.P. DE MOURA, M.E. DA S JÚNIOR, J.V. DE MELO, P.M. AZOUBEL AND E. DE A MELO. J. Bioprocess Biotech. 4: 1-9, 2014.

5.Frederick, K.J. Performance and problems of pharmaceutical suspensions. J. Pharm. Sci. 50: 531-535, 1961.

6.GHICA, M.V, M.G. ALBU, D., KAYA, L. POPA, S. ÖZTÜRK, L. RUSU, C. DINU-PÎRVU, C. CIPRIAN, L. ALBU, A. MEGHEA AND C. NITIPIR. Korean J. Chem. Eng. 33: 1325-1330, 2016.

7.GINOVART, M., LÓPEZ, D., GIRÓ, A. SILBERT, M., Flocculation in brewing yeasts: A computer simulation study. Biosystems 83: 51-55, 2006.

8.GOOSSENS, K., WILLAERT, R.. Flocculation protein structure and cell-cell adhesion mechanism in Saccharomyces cerevisiae. Biotechnol. Lett. 32: 1571-1585, 2010.

9.GRIEVE, D.G. Feed intake and growth of cattle fed liquid brewer's yeast. Can. J. Anim. Sci. 59: 89-9, 1979

10.HADZIABDIC, J., A. ELEZOVIC, O. RAHIC, I. MUJEZIN AND E. VRANIC. Int. J. Pharm. Compd. 19: 78-85, 2015.

11.HARLOW, B.E., BRYANT, R.W., COHEN, S.D., O'CONNELL, S.P., FLYTHE, M.D.. Lett. Appl. Microbiol. 63: 307-312, 2016.

12.KULSHRESHTHA, A., O. SINGH AND G. WALL (eds.). Pharmaceutical Suspensions: From Formulation Development to Manufacturing.
} 
New York, Springer, 2010.

13.KWIATKOWSKI, S., EDGAR S.. Yeast (Saccharomyces cerevisiae) glucan polysaccharides - occurrence, separation and application in food, feed and health industries. In: Karunaratne, D.N. editor. The Complex World of Polysaccharides. London, InTech., 2012.

14.LESMEISTER, K.E., HEINRICHS, A.J., GABLER, M.T.. J. Dairy. Sci. 87: 1832-1839, 2004.

15.MATHIAS, T.R.S., ALEXANDRE V.M.F., CAMMAROTA M.C., DE MELLO, P.P.M., SÉRVULO, E.F.C.. Characterization and determination of brewer's solid wastes composition. J. Inst. Brew. 121: 400-404, 2015.

16.NADPARA, N.P., THUMAR, R.V., KALOLA, V.N., PATEL, P.B.. Quality by design (QBD): A complete review. Int. J. Pharm. Sci. Rev. Res. 17: 20-28, 012.

17.NEWBOLD, C.J., WALLACE, R.J., MCINTOSH, F.M.. Mode of action of the yeast Saccharomyces cerevisiae as a feed additive for ruminants. Br. J. Nutr. 76: 249-261, 1996.

18.OWENS, F.N., SECRIST, D.S., HILL, W.J. GILL, D.R.. Acidosis in cattle: a review. J. Anim. Sci. 76: 275-286, 1998.

19.PATEL, R.P., PATEL, M.P., SUTHAR, A.M.. Indian J. Sci. Technol. 2: 44-47, 2009.

20.PATRA, A. 2012. Asian J. Anim. Vet. Adv. 7: 366-375.

21.POPA, L., GHICA, M.V., ALBU, M.G., ORTAN, A. DINU-PÎRVU, C.E. Dig. J. Nanomater. Bios. 8: 937-943, 2013.

22.POPPY, G.D., RABIEE, A.R., LEAN, I.J., SANCHEZ, W.K., DORTON, K.L. MORLEY, P.S. J. Dairy. Sci. 95: 6027-6041, 2012.

23.RATHORE, A.S., WINKLE, H. Nat. Biotechnol. 27: 26-34, 2009.

24.RETTA, K. Int. J. Livest. Prod. 7: 24-32, 2016.

25.SCHOTT, H. J. Pharm. Sci. 65: 855-861, 1976.

26.SOARES, E.V. J. Appl. Microbiol. 110: 1-18, 2011.

27.STEWART, G.G. , GORING, T.E., J. Inst. Brew. 82: 341-342, 1976.

28.TADROS, T., Adv. Colloid Interface Sci. 168: 263-277, 2011.

29.YU, L.X. Pharm. Res. 25: 781-791, 2008.

30.ZHU, W., ZHANG, B.X., YAO, K.Y., YOON, I., CHUNG, Y.H., WANG, J.K., LIU, J.X.. J. Anim. Sci. 29: 801-806, 2016.

Manuscript received: 27.08 .2019 